\title{
$\mathrm{DMD}$ 를 이용한 위상천이 모아레 3 차원 형상 측정
}

\author{
정경석 ${ }^{*}$, 정용상 ${ }^{2}$ \\ ${ }^{1}$ 한국기술교육대학교 기계정보공학부, ${ }^{2}$ 한국기술교육대학교 대학원 기계공학부
}

\section{Application of DMD for Phase Shifting in Moiré Topology}

\author{
Kyung-Seok Jeong $^{1^{*}}$ and Yongsang Jung ${ }^{2}$ \\ ${ }^{1}$ School of Mechanical Engineering, Korea University of Technology \& Education \\ ${ }^{2}$ Department of Mechanical Engineering, Graducate School, Korea University of Technology \& \\ Education
}

\begin{abstract}
요 약 생산방식의 변화에 따라 3차원 형상을 신속하고 정확하게 측정하는 것이 중요해졌다. 가장 훌륭한 비접촉 3 차원 측정방법인 모아레 방법 중 잡음신호를 효과적으로 제거할 수 있는 위상천이 방법을 구현함에 있어 $\mathrm{DMD}$ 를 이 용하여 격자를 생성하고 이송하는 효과를 발생하도록 하였다. 컴퓨터에서 격자를 이송하고 위상천이를 발생하므로 기 계적 이송으로 인한 잡음신호의 발생 가능성을 배제할 수 있으며 광학렌즈와의 적절한 조합을 통해 쉽게 분해능을 변화하며 3 차원 정보 획득이 가능하다. 근본적인 $2 \pi$ 모호성문제를 극복하기 위하여 2 차원 위상정력을 실시하였다. 이 방법을 적용하여 3 차원 형상의 측정을 수행하였다.
\end{abstract}

\begin{abstract}
The need for rapid and accurate measurement of 3-dimensional objects is increasing due to the paradigmatic shift in manufacturing from mass production to small batch production. A three dimensional measurement technique which can provide the dimensional information of the object manufactured or to be manufactured has been developed. This method is based on phase shifting moiré topology. Digital-Micromirror-Device (DMD) has been used in generating phase shifting moiré fringes. And the mechanically moving optical components used for phase shifting, which might result in measurement errors, have been replaced by the DMD. Inherent $2 \pi$-ambiguity problem, occurring in the calculation of phase from the light intensity distribution due to the nature of arctangent function, has been overcome by adapting the phase unwrapping method. The advantage of this technique is the easy change of the range and the resolution of the measurement by simply changing the computer generated grid pattern with the appropriate combination of projection lens of various focal length.
\end{abstract}

Key Words : 3-D Topography, Phase shifting, Moiré, Digital Micro-Mirror Device

\section{1. 서론}

제품의 생산방식이 대량생산으로부터 소량 다품종 생 산으로 변화함에 따라 설계 또는 역설계를 위해 신속하 고 정확하게 3차원 형상을 측정할 수 있는 방법이 매우 중요하게 되었으며, 모델링, 의학적 진단 응용, $\mathrm{CAD} / \mathrm{CAM}$, 멀티미디어 및 가상현실 시스템 등과 같이 다양한 산업분야에서 그 응용분야가 확장되고 있다.
모아레 방법은 Meadows [1] and Takasaki [2]에 의해 소개된 이래 3 차원 형상을 측정하는 가장 훌륭한 방법 중 하나로 간주되고 있다. 그 구현방법으로는 그림자법과 투 영법이 있다. 그림자법은 구성이 간단하다는 장점을 가지 고 있지만 대상물체가 격자에 가까워야 한다는 제약을 가지고 있기 때문에 그 단점을 보완하여 투영법이 도입 되었다.

투영법에서는 투영격자를 통해 광을 입사하여 물체 표

*교신저자 : 정경석(jks@kut.ac.kr) 
면에 밝고 어두운 무늬가 반복되어 생성되도록 하고 이 를 관찰격자를 통해 관찰할 때 모아레 간섭무늬가 생성 되는 것을 이용하는 방법이다. 간섭무늬가 생성된 상태에 서 물체를 격자에 수직한 방향으로 움직이면 모아레 간 섭무늬의 위상이 변화하는데, 이러한 현상을 이용하여 높 이가 변화하는 물체 표면에 생성되는 간섭무늬의 위상 변화를 파악함으로써 대상물체 표면의 높이를 알 수 있 게 된다.

이 때 간섭무늬는 광학적 또는 디지털 복조 방법 등 다양한 방법으로 생성될 수 있다. 디지털 방법의 경우 물 체표면에서 변형된 격자 영상에 컴퓨터에서 생성된 격자 영상을 합성하는 방법[3] 또는 컴퓨터에 미리 저장된 변 형 이전의 격자 영상과 합성하는 방법[4] 등이 시도되었 다. 그런데 광학적이나 디지털 복조 방법 모두 투영 및 복조 격자에 의한 잡음 영상이 발생하는 문제가 있다. 이 러한 종류의 잡음은 입사 및 관찰 격자의 상대위치를 고 정한 채 동시에 격자무늬에 수직한 방향으로 이동하면서 다중의 영상을 획득하는 방법을 적용하여 격자 잡음이 제거된 간섭무늬를 얻을 수 있다.

이를 구현하기 위해 투영 격자와 관찰 격자를 일체로 하여 기계적으로 이동하거나[5], $\mathrm{LCD}$ 를 이용해 격자를 생성하고 $\mathrm{LCD}$ 를 기계적으로 이송시킴으로써 위상천이 가 발생하도록 하는 등의 여러 방법이 시도되었다[6]. 이 러한 경우 모두 기계적 이송에 따른 진동으로 인해 잡음 이 발생할 가능성을 가지고 있다. 따라서 본 연구에서는 기계적인 격자 이송방식을 대체하기 위하여 Digital Mirror Device(DMD)를 이용하여 격자를 생성하고 이송 효과를 발생할 수 있는 방안을 구현한다.

\section{2. 이론적 배경}

\section{1 위상천이 투영 모아레법}

투영 모아레법은 투영과 복조 시 격자 선 잡음이 발생 하는 문제를 가지고 있다. 간섭무늬를 공간적으로 필터링 함으로써 선명한 모아레 간섭무늬를 얻을 수도 있지만[5] 이에 따른 공간분해능의 저하를 감수해야 한다. 이러한 문제를 해결하기 위한 다른 방법으로 투영 및 관찰 격자 를 이동하면서 중복되는 영상을 획득하는 방법이 있다. 투영 및 관찰 격자가 상대적인 병진 이동을 하면 물체표 면에 형성된 모아레 간섭무늬의 위치와 위상 또한 변화 한다. 이렇게 이동하며 3 개 이상의 위상천이 모아레 간섭 무늬 영상을 획득하면, 각 측정 점에서의 밝기 변화로부 터 정확한 높이정보를 계산해낼 수 있다[7,8]. 두 격자의
상대적 위치를 고정한 채 동시에 이송하면 모아레 간섭 무늬의 위치는 변화하지 않는다. 격자를 이송하는 기간 동안의 영상을 중첩하면 격자 잡음이 제거된다[5,9].

\section{2 $\mathrm{DMD}$ 를 이용한 위상 천이 투영 모아레법}

그림 1 은 기존에 제안된 위상 천이 투영 모아레법[10] 에서 기계적으로 이송하여 위상천이를 구현한 것을 본 연구에서 $\mathrm{DMD}$ 를 이용하여 격자를 발생하고 이송하는 효과가 구현되도록 한 광학배치의 개략도이다. 이렇게 $\mathrm{DMD}$ 를 이용하여 격자의 생성과 이송을 구현하면 기계 적 이송장치를 대체함으로써 구성요소의 물리적 이동에 따른 잡음신호의 발생가능성을 배제하면서 분해능을 변 화하기 위한 목적 등으로 격자 특성을 변경하는 것이 용 이하게 되는 장점이 있다.

격자의 크기 또는 주기 등의 특성은 $\mathrm{DMD}$ 에 연결된 컴퓨터에서 변화하며 생성할 수 있다. 이렇게 생성된 격 자의 광 강도 분포는 식(1)과 같다.

$T_{p}(x)=A\left[1+\cos \frac{2 \pi x}{g}\right]$

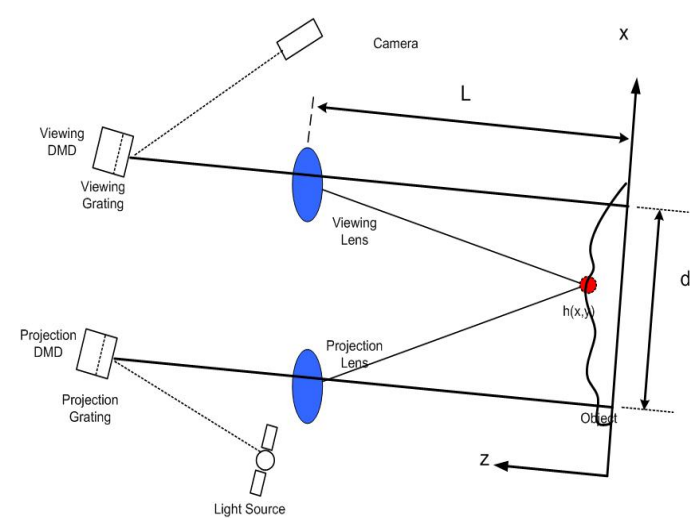

[그림 1] $\mathrm{DMD}$ 를 이용한 위상 천이 투영 모아레 광학 배열

[Fig. 1] Optical arrangement of phase shifting Moire using DMD

여기서 $\mathrm{A}$ 와 $\mathrm{g}$ 는 각각 $\mathrm{DMD}$ 에서의 생성되는 격자 진 폭과 피치이다. 격자의 특성은 한 주기에 포함되는 픽셀 수에 따라 달라진다. 그림 2는 1주기를 이루는 픽셀 수가 다른 경우의 격자 모양이다. 


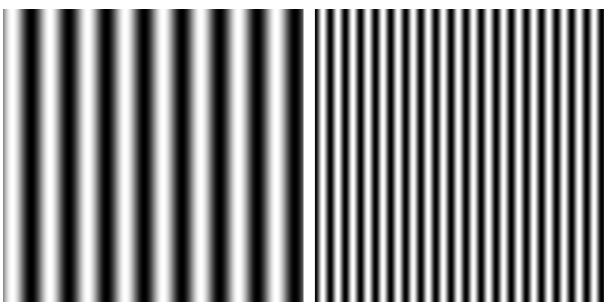

[그림 2] 64 및 128 픽셀 주기의 격자

[Fig. 2] Generated grating of frequency 64 and 128 pixel

이러한 격자를 를 대상목표에 투영하였을 때의 광강도 분포는 식(2)와 같다.

$$
\begin{aligned}
I_{p}(x, y)= & I_{s} R(x, y) A[1+ \\
& \left.\cos \frac{2 \pi\left(x+h(x, y) \tan \theta_{i}\right)}{m_{p} g}\right]
\end{aligned}
$$

여기서 $m_{p}$ 는 투영렌즈 배율, $\mathrm{h}(\mathrm{x}, \mathrm{y})$ 는 위치 $P(x, y)$ 에서 대상목표의 높이, $\theta_{1}$ 은 $P(x, y)$ 에의 입사각, $I_{s}$ 는 광원의 강도, $R(x, y)$ 는 대상목표의 반사율이다.

관찰 격자는 투영 격자와 동일한 피치를 가지도록 한 다. 식의 유도를 단순화하기 위해 관찰 $\mathrm{DMD}$ 에 의해 생 성되는 격자가 대상물 상에 비춰져 왜곡되는 것으로 가 정하면 광 강도 분포는 식(3)과 같이 된다.

$$
\begin{aligned}
I_{r}(x, y)= & A[1+ \\
& \left.\cos \frac{2 \pi\left((x-\delta)+h(x, y) \tan \theta_{i}\right)}{m_{p} g}\right]
\end{aligned}
$$

여기서 $\delta$ 는 투영 격자와 관찰 격자의 위상차이다. 이 때 형성되는 1 차 모아레 간섭무늬의 강도는 식 (4)와 같 다.

$$
\begin{array}{r}
I(x, y)=I_{s} R(x, y) A^{2}\left[1+\cos \frac{2 \pi}{m_{p} g}\right. \\
\\
\left.h(x, y)\left(\tan \theta_{1}-\tan \theta_{2}\right)+\delta\right]
\end{array}
$$

위상천이 법에 의한 모아레 간섭무늬는 전자기파 간섭 과 유사하므로 동일한 해석방법을 적용할 수 있다. 이를 위해 모아레 간섭무늬 강도분포 식(4)를 다음의 형식으로 나타낸다.

$$
I_{r}(x, y)=B[1+\cos (\Phi(x, y)+\Delta)]
$$

여기서 $\Delta$ 는 $\Delta=\frac{2 \pi \delta}{m_{p} g}$ 인 위상천이 이며, $\Phi(x, y)$ 는 단면분포 $h(x, y)$ 에 따라 결정되는 상대 위상이다.

$$
h(x, y)=\frac{\lambda_{e q}}{2 \pi} \Phi(x, y)
$$

이 때 등가파장 $\lambda_{e q} \equiv \frac{m g}{\tan \theta_{1}-\tan \theta_{2}}$ 이다.

$\operatorname{Kim}$ 등[10]은 $h(x, y)$ 가 동작거리 $l$ 에 비해 충분히 작으면 등가파장이 일정한 것으로 가정할 수 있다는 것 을 보이고 위상천이 간섭무늬 해석 기법이 위상 $\Phi(x, y)$ 의 정확한 결정에 적용될 수 있음을 보였다.

$$
\lambda_{e q}=\frac{l^{2}}{f d}\left(1-\frac{f}{l}\right)
$$

위상차가 $\Delta=0, \frac{\pi}{2}, \pi, \frac{3 \pi}{2}$ 이 되도록 격자를 생성하 고 4-Bucket 법[4]을 적용하면 위상 $\Phi(x, y)$ 는 식(8)과 같다.

$$
\Phi(x, y)=\tan ^{-1}\left[\frac{I_{4}(x, y)-I_{2}(x, y)}{I_{1}(x, y)-I_{3}(x, y)}\right]
$$

이렇게 구해진 위상값 분포는 식(6)을 이용하여 높이 분포로 변환될 수 있다.

\section{3 영상의 시간 적분}

식(5)에서 가시성 항은 사인함수 형태로 표현되므로 시간과 격자 이송속도의 곱이 격자 피치의 정수배가 될 때는 0 이 된다. 또는 노출시간이 충분히 길게 되면 격자 의 효과는 무시할 수 있게 된다. 그러므로 영상 시간적분 방법을 적용하여 격자 잡음신호를 제거하였다. 투영 및 관찰 격자를 동일한 속도로 이동하며 노출시간을 충분히 길게 하여 영상을 획득하면 격자 잡음신호가 없는 영상 이 획득될 수 있다.

\subsection{2차원 위상 정렬}

기록된 영상 정보를 식(8)에 대입하고 계산을 수행하 면 대상물 각 위치에서의 위상정보를 얻을 수 있고, 이로 부터 높이 정보를 추출할 수 있다. 그러나 여기에는 $2 \pi$ 의 주기를 가지는 아크탄젠트 함수의 계산으로 인해 근 본적인 $2 \pi$-모호성 문제를 가지고 있다, 이로 인해 높이 
의 변화율이 일정 값 이상이 될 수 없으며, 그 결과 실제 위상은 측정된 자료로부터 계산된 위상과 $2 \pi$ 의 정수배 만큼 차이를 가질 수 있다.

$$
\begin{array}{r}
\Phi_{r i}(x, y)=\Phi_{r i}(x, y)+2 \pi K_{i}, \\
K_{i}=0, \pm 1, \pm 2, \ldots .
\end{array}
$$

여기서 $\Phi_{r i}(x, y)$ 와 $\Phi_{m i}(x, y)$ 는 각각 실제위상과 측 정된 위상을 나타낸다. 그 차이는 위상정렬법을 이용하여 구할 수 있다.

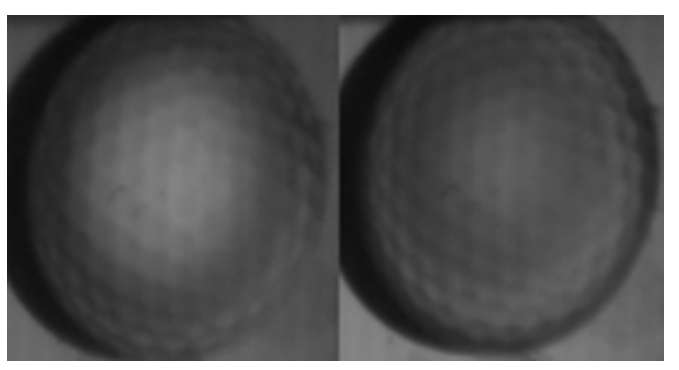

$$
\Delta=0 \quad \Delta=\frac{\pi}{2}
$$

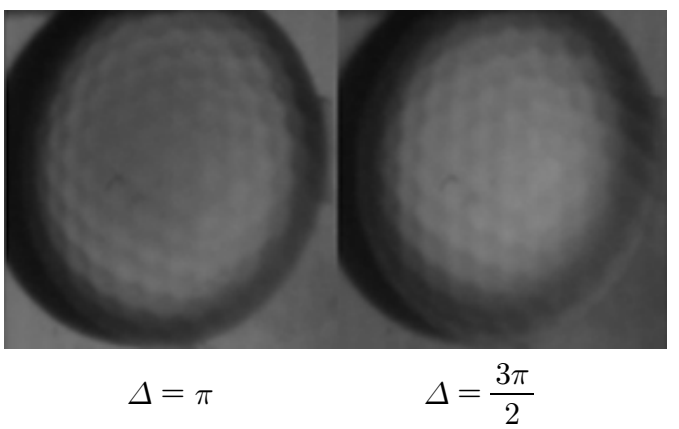

[그림 3] 격자 간 위상차에 따른 위상천이 시간적분 영상

[Fig. 3] Phase shifted time integral image for each phase difference

본 연구에서는 전체 측정 영역에서 인접한 점과의 위 상을 비교하는 2 차원 위상정렬법을 적용하여 적절한 $K_{i}$ 값을 구한다.

\section{3. 실험}

\section{1 실험방법}

그림 1 과 같이 광학배열을 하고 컴퓨터를 이용하여 대 상물체의 크기와 원하는 해상도를 구현할 수 있는 격자 가 발생되도록 하고, 투영 및 관찰 $\mathrm{DMD}$ 에 의해 생성되
는 격자 간의 위상차가 $\Delta=0, \frac{\pi}{2}, \pi, \frac{3 \pi}{2}$ 로 유지되면 서 위상천이 효과가 발생하도록 하며 디지털카메라를 이 용하여 시간적분 영상을 기록한다. 이 때 노출시간은 광 량에 따라 변화하지만 격자 잡음신호가 없는 영상이 획 득될 수 있도록 10 주기 이상 진행될 수 있는 충분한 노출 을 하였다.

시간적분 영상을 4-Bucket법을 이용하는 식(8)에 대입 하여 위상을 계산하고 2차원 위상정력법을 적용하여 실 제위상을 구한다.

\section{2 실험결과}

딤플이 있는 골프공을 대상으로 본 연구방법을 적용하 여 측정을 하였다. 그림 3의 영상을 4-Bucket 법을 이용 하는 식 (8)에 적용하여 각 점 $P(x, y)$ 의 위상을 계산하 였다. 이를 식(6)에 대입하여 높이 분포로 변환한 것을 그 림 4에 보였다. 골프공의 딤플까지 잘 구분되는 것을 볼 수 있으며 이로부터 본 연구방법을 적용하여 3 차원 축정 이 가능함을 확인할 수 있다.
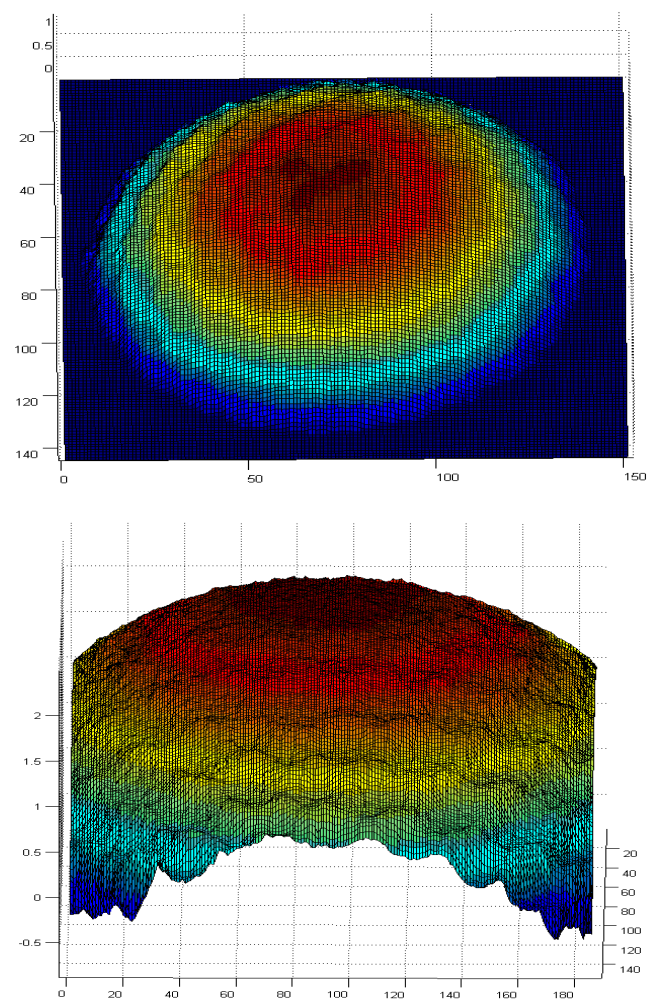

[그림 4] 골프공의 형상 측정 결과

[Fig. 4] Trial application of the method to the measurement of a golf ball 


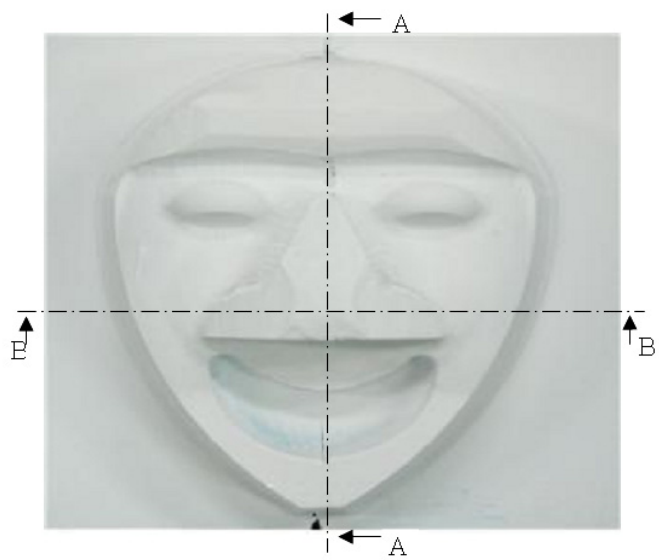

(a) 탈 모양 대상 및 비교 단면

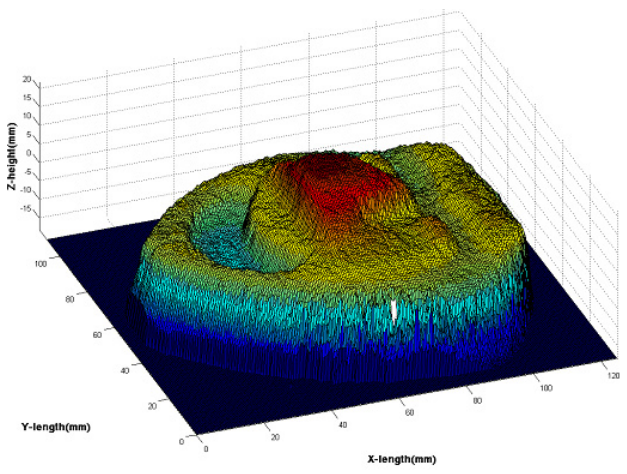

(b) 3 차원 측정결과

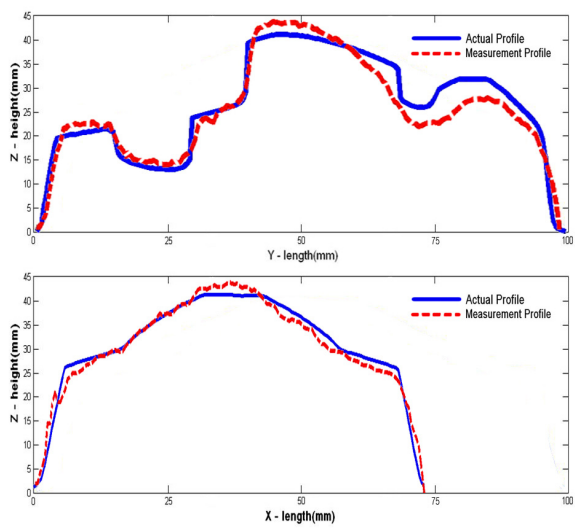

(c) A-A 및 B-B 단면의 높이 변화

[그림 5] 탈모양 대상에 대한 측정 결과

[Fig. 5] Comparison of the measurement results and actual profile
그림 5는 가로 $80 \mathrm{~mm}$, 세로 $100 \mathrm{~mm}$ 인 탈모양의 대상 물체에 적용한 결과이다. (a)는 대상물체 2 차원 영상이고, (b)는 측정결과를 보인 것이다. (c)는 (a)에 표시된 A-A 및 B-B 단면에서의 높이 실측값과 본 방법에 의한 측정 결과를 비교하여 나타낸 것이다. 전체적인 형상의 측정이 가능함을 보여주고 있으나 수직방향 높이 변화가 있는 주변에서의 상대적으로 큰 오차가 발생하며, 본 경우에서 의 최대오차는 $9.8 \%$ 이다. 이는 위상이 식(8)과 같이 $\arctan$ 함수로 표현되기 때문에 발생하는 것으로 투영 및 관찰격자의 분해능 향상을 통해 그 오차를 줄이는 것이 가능하다.

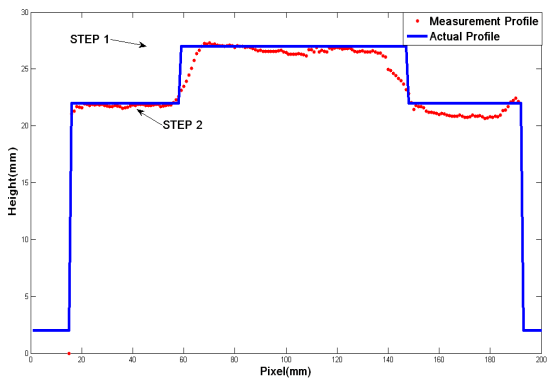

[그림 6] 계단형 대상에서의 측정 오차

[Fig. 6] Estimation of the measurement error for an object with step change in height

그림 6은 수직방향의 높이 변화가 있는 경우의 오차를 측정하기 위하여 계단형 대상에 적용하여 실제 높이와 본 방법으로 측정된 높이를 비교하여 나타낸 것이다. 전 체적으로 높이를 잘 측정할 수 있으나, 높이 변화가 급격 한 곳에서는투영 및 관찰 시의 그림자 영향으로 인해 오 차가 발생하는 것을 볼 수 있다. 측정부분이 가려지기 때 문에 발생하는 이런 종류의 오차를 완전히 배제할 수는 없지만 격자의 특성과 렌즈의 초점거리의 적절한 조합을 통하여 오차의 범위를 조절하는 것이 가능하다.

\section{4. 결론}

기존의 위상천이 투영 모아레법에 적용된 기계적인 격 자를 이송 방법을 $\mathrm{DMD}$ 를 이용하여 격자를 생성하고 이 송하는 효과를 내는 방법으로 대체하여 비접촉 광학적 방법으로 3 차원 형상을 측정하는 방법을 개발하여 다음 의 결론을 얻었다.

1. $\mathrm{DMD}$ 를 이용하여 격자 이송의 효과를 냄으로써 기 계적으로 격자를 이송할 때 발생할 수 있는 진동 등 
으로 인한 잡음신호의 발생을 배제할 수 있다.

2. 투영 및 관찰 격자가 설정된 위상차를 유지하며 동 일한 속도로 이송되는 효과를 내고 적정 시간 연속 노출하는 시간적분 영상법을 적용함으로써 영상 이 미지에 포함되는 배경신호 잡음, 격자 잡음신호들 을 제거하는 것이 가능하다. 본질적인 $2 \pi$ 모호성 문제는 2차원 위상정렬 방법으로 해결하였다.

3. 수직방향으로 높이 변화가 크지 않은 경우 좋은 3 차원 측정결과를 얻을 수 있다. 높이 변화가 큰 경 우 격자의 분해능과 렌즈의 조합을 통해 오차를 최 소화하여야 한다.

4. 이 방법을 이용하면 생성되는 격자 특성 및 렌즈 초 점거리의 적절한 조합을 통해 측정 시스템이 다양 한 크기에 대해 다양한 해상도를 가지도록 변화하 는 것이 용이하다.

\section{References}

[1] D. Meadows, W. Johnson, and J. Allen, "Generation of surface contours by moiré patterns," Appl. Opt. 9,942 7, 1970.

[2] H. Takasaki, "Moiré topography," Appl. Opt. 9,1467 $72,1970$.

[3] R. Martinez-Celorio, J. Dirckx, J. Buytaert, L.M. Lopez, and W. Decraemer, "Modified temporal-phase-unwrapping method for measuring in real time the out-of-plane displacements of the tympanic membrane of Mongolian gerbil," Opt. Int. J Light Electron Opt. 119,783-7, 2008. :phase shifted unwrapping

[4] J. Dirckx and W. Decraemer, "Optoelectronic Moiré projector for real-time shape and deformation studies of the tympanic membrane," J Biomed Opt. 2(2),176 - 85, 1997.

[5] H. Takasaki, "Moiré topography from its birth to practical applications," Opt. Lasers Eng. 3,3-13, 1982.

[6] J.A.N. Buytaert and J.J.J. Dirckx, "Phase-shifting Moiré topography using optical demodulation on liquid crystal matrices," Opt. Lasers Eng. 48,172 - 181, 2010.

[7] J. Lianhua, K. Yutaka, Y. Toru, and O. Yukitoshi, "Shadow moiré profilometry using the phase-shifting method," Opt. Eng. 39(8), 2119 - 2123, 2000.

[8] W. Osten, "Digital processing and evaluation of fringe patterns in optical metrology and non-destructive testing," in Optical methods in experimental solid mechanics, p.308-63, Springer, Berlin, 2000.
[9] J. Dirckx, W. Decraemer, and M. Eyckmans, "Grating noise removal in Moire' topography," Opt. Int. J Light Electron Opt 86,107-10, 1990.

[10] S. Kim, Y. Choi, and J. Oh, "Reverse engineering: high speed digitization of free-form surfaces by phase-shifting grating projection moiré topography," Int. J of Machine Tools \& Manufacture 39,389 - 401, 1999.

정 경 석(Kyung-Seok Jeong)

[정회원]

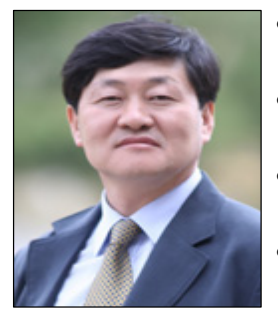

- 1989년 2월 : 서울대학교 대학원 항공공학과 (공학박사)

- 1989년 2월 : 대우자동차 기술연 구소 선임연구원

- 1990년 5월 : Imperial College 연구원

- 1992년 9월 현재 : 한국기술 교육대학교기계정보공학과 교수

<관심분야>

광응용, 열유체 계측

정 용 상(Yongsang Jung)

[정회원]

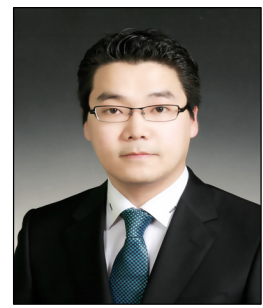

- 2009년 2월 : 한국기술교육대학 교 대학원 기계공학과 (공학석 사)

- 2009년 8월 현재 : (주)ㅆ트렉 아이 연구원

<관심분야>

광응용, 열유체 수치모사 